\title{
Habilidades transcomplejas para la justicia social en tiempos de pandemia y post-pandemia SARS-COV-2
}

\author{
Juan Miguel González Velasco ${ }^{1}$ \\ https://orcid.org/0000-0002-3502-2539 \\ Marlene Zwierewicz ${ }^{2}$ \\ http://orcid.org/0000-0002-5840-1136 \\ Vera Lúcia Simão ${ }^{3}$ \\ https://orcid.org/0000-0001-6169-0242
}

\section{Resumen}

La educación mundial enfrenta una verdadera crisis a causa de una pandemia viral obligando a que millones de estudiantes y miles de escuelas y universidades dejen su modo presencial hacia lo virtual ¿Cómo afrontar estratégicamente la formación estudiantil tomando en consideración las multivariables que el momento implica? La labor del docente cambia o se transforma, la escuela y su gran labor social está en resiliencia y el estudiante en su nuevo modo de autoaprendizaje, pero muchos sufren por la exclusión escolar que se profundiza con la crisis. El objetivo de este artículo es presentar alternativas para que la educación actúe de forma a comprometerse con la justicia social en las fases de supresión y de recuperación de la pandemia que ocurren durante y en el post-confinamiento. Para esta investigación bibliográfica se aplicó la Teoría Fundamentada (GLASEL; STRAUSS, 1967) para el desarrollo del R3 a partir del análisis de dos artículos de González (2009) y de OMS (2020), logrando generar procesos de codificación y la generación categorial de retos, pero también de condiciones que puedan dar respuesta a la Pandemia y Post-pandemia SARS-coV-2. Como resultados se presentan la descripción de retos institucionales, del profesor y del estudiante y reflexiones de cómo encarar

${ }^{1}$ Facultad de Ciencias Farmacéuticas y Bioquímicas. Universidad Mayor de San Andrés - UMSA, La Paz, Bolívia. Farmacéutico. Doctor y Postdoctor en Educación. Catedrático Epidemiología y Salud Pública. E-mail: jmgonzales9@umsa.bo. Autor de Correspondencia.

${ }^{2}$ Doctora en Psicología por la Universidad Federal de Santa Catarina (UFSC) y Doctora en Educación por la Universidad de Jaén (UJA). Coordinadora e investigadora del Programa de Maestría de la Universidade Alto Vale do Rio do Peixe (UNIARP). Coordinadora adjunta de la Red Internacional de Escuelas Creativas (RIEC). E-mail: marlenezwie@yahoo.com.br.

3 Doctora en Educación y Sociedad por la Universidad de Barcelona (UB). del Programa de Maestría de la Universidade Alto Vale do Rio do Peixe (UNIARP). Miembro de la Red Internacional de Escuelas Creativas (RIEC) - RIEC; RIEC FURB; RIEC UNIARP; RIEC ECOFOR. E-mail: vsimao2@gmail.com. 
las adversidades teniendo en cuenta nuevas habilidades transcomplejas vinculadas a una Educación R3: Reinventada, Religada y Resiliente.

Palabrasclave: Justicia social, Educación, Autoaprendizaje, Estudiantes, Habilidades transcomplejas.

\title{
Transcomplex skills for social justice in times of pandemic and post-pandemic SARS-COV-2
}

\begin{abstract}
World education faces a true crisis due to a viral pandemic forcing millions of students and thousands of schools and universities to leave their face-to-face mode towards the virtual. How to strategically face student training taking into consideration the multivariables that the moment implies? The teacher's work changes or is transformed, the school and its great social work is in resilience and the student in her new mode of self-learning, but many suffer from school exclusion that deepens with the crisis. The objective of this article is to present alternatives for education to act in order to commit to social justice in the phases of suppression and recovery from the pandemic that occur during and after confinement. For this bibliographic research, Grounded Theory (GLASEL; STRAUSS, 1967) was applied for the development of R3 from the analysis of two articles by González (2009) and OMS (2020), managing to generate coding processes and the categorical generation of challenges, but also conditions that can respond to the SARS-coV-2 Pandemic and Post-pandemic. As results, the description of institutional, teacher and student challenges and reflections on how to face adversities are presented taking into account new transcomplex skills linked to an R3 Education: Reinvented, Religated and Resilient.
\end{abstract}

Keywords: Social justice, Education, Self-learning, Student, Transcomplex skills.

\section{Introducción}

Finalizando el 2019, en el mes de diciembre en la ciudad de Wuhan, China se convirtió en el epicentro de un brote de neumonía de etiología desconocida cuyo agente causal fue identificado como un nuevo coronavirus (2019-nCoV) posteriormente clasificado como SARS-CoV2 causante de la enfermedad COVID-19 (LU; STRATTON; TANG, 2020, CHENG et al., 2020). Primero el 30 de enero se habían reportado 9.692 casos en toda China y 90 casos en diferentes países incluyendo Taiwán, Tailandia, Vietnam, Malasia, Nepal, Sri Lanka, Camboya, Japón, Singapur, la República de Corea, Emiratos Árabes Unidos, Estados Unidos, Filipinas, India, Irán, Australia, Canadá, Finlandia, Francia y Alemania (WANG; TANG; WEI, 2020, HOLSHUE et al. 2020). Tres meses después, de manera más precisa el 11 
de marzo del 2020, la Organización Mundial de Salud declara a esta enfermedad como una pandemia.

El primer nombre adoptado para este nuevo virus fue de manera temporal 2019-nCoV, que engloba a una enfermedad con signos y síntomas definidos diferentes a los coronavirus ya conocidos (VELAVAN; MEYER, 2020). Es importante saber que hasta el momento se conocían un total de 36 coronavirus. Los virus de la familia coronaviridae, conocidos como coronavirus, son virus de tipo ARN positivo de cadena simple, envueltos en cápside que pueden afectar un amplio rango de animales e incluso a humanos. Fueron descritos por primera vez por Tyrell y Byone en 1966 (VELAVAN; MEYER, 2020).

Poco a poco la pandemia se ha convertido en uno de los más grandes “[...] retos sanitarios en escala global de este siglo [...]" (WERNECK; CARVALHO, 2020, p. 1). A partir de entonces ha generado incertidumbres que afectan no sólo el área de la salud, pero también la cultura, la economía y otras condiciones relacionadas a la vida en el planeta. Si antes de la pandemia Morin (2015) ya indicaba como grandes problemas de la humanidad el desreglamento ecológico, la exploración sin límites de los recursos de la naturaleza, la búsqueda deshumana por logros, la ampliación de las desigualdades sociales, ahora ya se agrupan a estos problemas otras adversidades que afectan la realidad actual y afectarán la futura, profundizando la exclusión social.

Además, estos problemas están lejos de una solución, ya que para Werneck y Carvalho (2020) la pandemia comprehende a cuatro fases contención, mitigación, supresión y recuperación - indicando que aún hay mucho tiempo para que la vida vuelva a una rutina que supuestamente no será igual a la anterior a la pandemia. Los autores registran que la fase de contención inicia antes del registro de casos en un país o región, la de mitigación cuando la transmisión ya está instalada en el país y se necesita disminuir los niveles de transmisión de la enfermad para grupos de riesgos, además del aislamiento de los casos positivos, la de supresión cuando se hace necesario intentar resultados no alcanzados en la etapa anterior, exigiendo más medidas para retrasar al máximo la explosión de casos, asegurando el tiempo necesario para establecerse las condiciones para evitar el colapso de la atención a la salud y, por último, la de recuperación cuando hay señales claros de involución de la epidémica con números de casos residuales y es cuando se 
“[...] requiere una organización de la sociedad para restructuración social y económica del país. Y, por supuesto, la intervención del Estado" (p. 2).

A pesar de no haber una fase que se pueda decir que todos los países vivencian actualmente, además de la preocupación con una segunda ola que puede ocurrir en tiempos distintos en los diferentes países, este artículo tiene como reflexión los cambios implicados especialmente en las fases de supresión y de recuperación. En la primera las personas están confinadas y en la segunda es cuando gravativamente la población confinada vuelve a sus actividades presencialmente y los estudiantes a las escuelas.

Con el objetivo de presentar alternativas para que la educación actúe en las fases de supresión y recuperación de la pandemia de forma a estar comprometida con la justicia social, el artículo discute posibilidades teóricoprácticas que pueden ayudar a las escuelas a proponer intervenciones y a los docentes a superar a las adversidades. Son contribuciones que involucran habilidades transcomplejas, indispensables para enfrentar la complejidad presente y, posiblemente, futura.

\section{La emergencia de cambios paradigmáticos en la educación}

En el año de 1993, Edgar Morin ha publicado con Anne Brigitte Kern el libro Terra-Pátria. El texto hace un prenuncio de la realidad que hoy. Además, han dejado claro que "Las advertencias y los alertas se multiplican sin éxito y solo demasiado tarde consiguen vencer las inercias y las cegueras, siendo necesario llegar al desastre para que una respuesta se reorganice" (MORIN; KERN, 2005, p. 154).

¡Hemos llegado al desastre! La inercia delante las alertas nos ha llevado a un caos deshumanizante al profundizar la injusticia social. Hay que tomar posición y una de las opciones es la que han manifestado Morin y Delgado (2017) años antes de la pandemia, o sea, la opción de abogar por la esperanza, identificando posibilidades de acción, asumiendo riesgos y produciendo los cambios para superar la catástrofe, moviéndose por la solidaridad y por iniciativas creadoras.

Por lo tanto, es tiempo de cambios paradigmáticos y no programáticos como afirma Morin (2007), pues la "[...] hiperespecialización impide de ver el global (lo que ella fragmenta en partes), bien como lo esencial (que ella diluye)" y la "[...] fragmentación de las asignaturas torna imposible 
aprehender 'lo que es tejido yunto, o sea, el complejo [...] (MORIN, 2009, p. 13-14), incluso la propia injusticia social, sus causas y consecuencias.

González (2017) apunta como posibilidad el paradigma complejotransdisciplinar, o sea, el transcomplejo. Este paradigma tiene como referencia el pensamiento ecologizador de la educación, el diálogo entre los diferentes saberes y el manejo de las incertidumbres en las cuales se incluyen los problemas derivados de la falta de justicia social y, por supuesto, la escuela.

Este artículo tiene el transcomplejo como referencia paradigmática, pues su dinamización en el contexto escolar posibilita la confluencia de estrategias creativas y el desarrollo de habilidades transcomplejas indispensables para enfrentar las incertidumbres generadas, especialmente en las fases de supresión y recuperación de la pandemia, valorando la inclusión de todos los estudiantes en el contexto escolar, sea de forma remota o presencial.

\section{Método}

Considerando el objetivo del estudio, se presentan alternativas para que la educación actúe en las fases de supresión y de recuperación de la pandemia que ocurre durante y en el post-confinamiento. Para esta investigación se aplicó la Teoría Fundamentada (GLASEL; STRAUSS, 1967) para el desarrollo del R3 a partir del análisis de dos artículos (GONZÁLEZ, 2009, OMS, 2020), logrando generar los procesos de codificación y la generación categorial para el desarrollo de las habilidades transcomplejas.

En el Cuadro 1 se presenta el diseño de la investigación. Las cuatro etapas que empiezan por la recogida de datos en los artículos, siguen por la organización y análisis hasta el desarrollo de la teoría formal por el método de comparación constante de la teoría a partir de la saturación teórica alcanzada en el estudio.

En el proceso se ha utilizado tres tipos de codificación: la codificación abierta, la codificación axial; la codificación selectiva. En la primera se ha identificado dos bloques de categoriales por autor, en la segunda la emergencia categorial, subcategorías, hipótesis y la Teoría Sustantiva ${ }^{4}$.

\footnotetext{
${ }^{4}$ La Teoría Sustantiva es aquella teoría desarrollada a partir de la interacción permanente que debe existir entre datos sin procesar y el análisis de los mismos, y que el investigador debe lograr desde el comienzo de la investigación para el logro dela teoría formal.
} 
Cuadro 1 - Diseño metodológico para la categorización y subcategorización

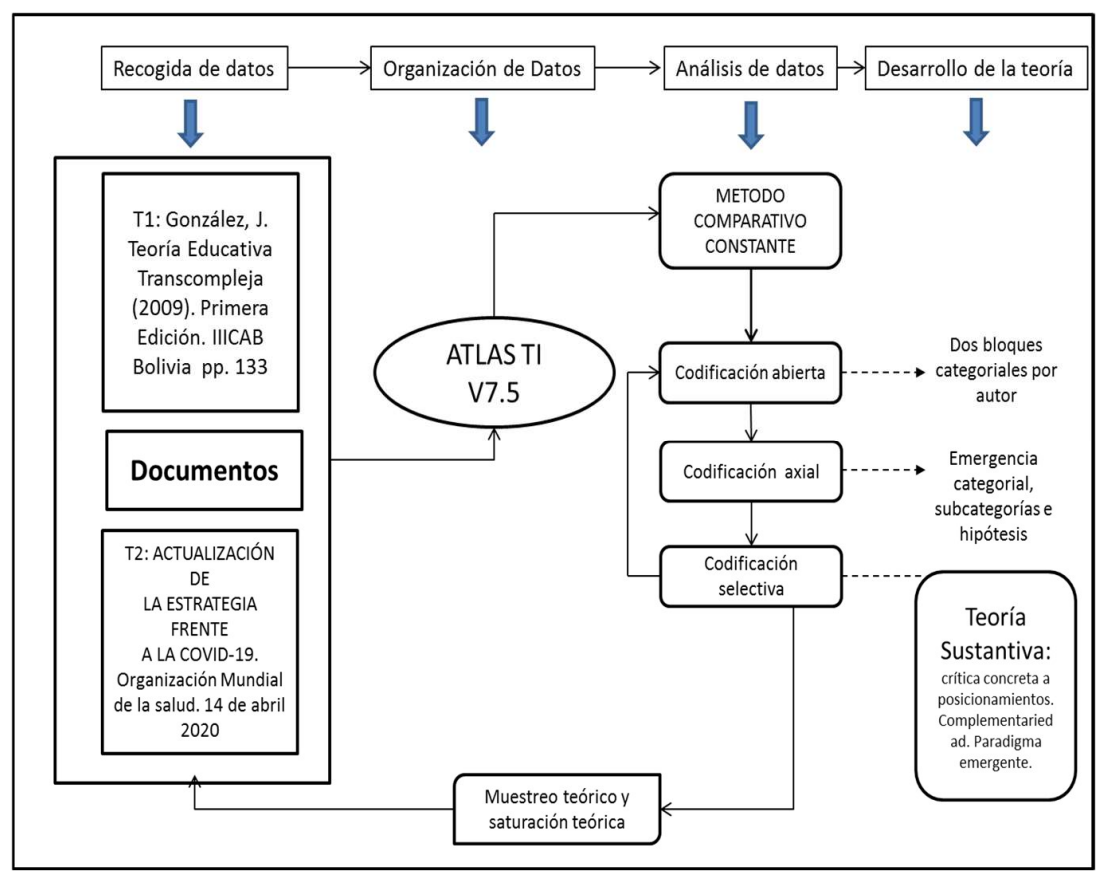

Fuente: Elaboración propia

\section{Resultados}

La investigación presentada se basa sobre el análisis de la Teoría Fundamentada de dos textos: T1 - Teoría Educativa Transcompleja de González (2009); T2 - Actualización de la estrategia frente a la COVID 19 de la OMS (2020). Se han hecho codificados a partir del uso de Atlas ti 7.5, que permitió la codificación abierta, axial y selectiva para la obtención de Teoría Sustantiva con procesos de saturación teórica.

La recogida de datos, tuvo un total de 12 memos de análisis generados y 16 citas observadas a partir de la organización de los datos en el software Atlas ti versión 7.5. 
Como parte del proceso se logró emerger 16 categorías secundarias a partir de codificación abierta y axial. Como parte de la codificación selectiva se ha identificado 4 categorías centrales complementarias al posicionamiento de ambas posturas científicas. Se logra construir Teoría Sustantiva consolidada bajo una postura complementaria y dialogada de los dos autores principales.

\section{Codificación abierta a partir de la TF}

En la codificación abierta se ha identificado bloques categoriales por autor: ocho en González (2009) y ocho en OMS (2020) (ver Figura 1):

Figura 1 - Bloques categoriales identificados en la codificación abierta

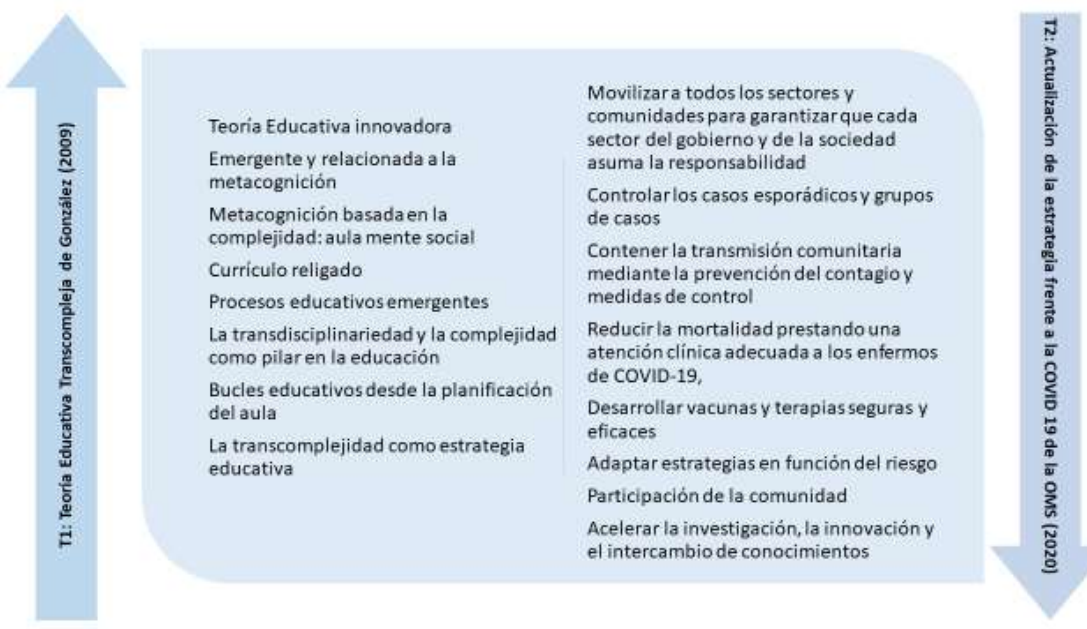

Fuente: Elaboración propia.

\section{Análisis de la codificación axial}

El texto T1 nace de una relación emergente de categorías basada en el relacionamiento estratégico educativo, como fundamento del pensamiento complejo en base a principios fundamentales, inmersos en procesos de un paradigma complejo asociado a la incertidumbre. Sus categorías centrales para T1 fueron aula mente social, currículo transcomplejo y estrategia educativa. Para el texto T2 se articula la estrategia emergente en salud, el trabajo 
comunitario y los procesos adaptativos como articulación estratégica en salud. Sus principales categorías fueron adaptación, estrategia emergente $y$ comunidad.

\section{Teoría Sustantiva}

La estructura emergente de la propuesta genera una relación directa prospectiva de análisis de categorías que permite generar estrategias educativas explicadas (ver Figura 2): 19

Figura 2 - Esferas educativas Pandémicas y Post-pandémicas COVID-

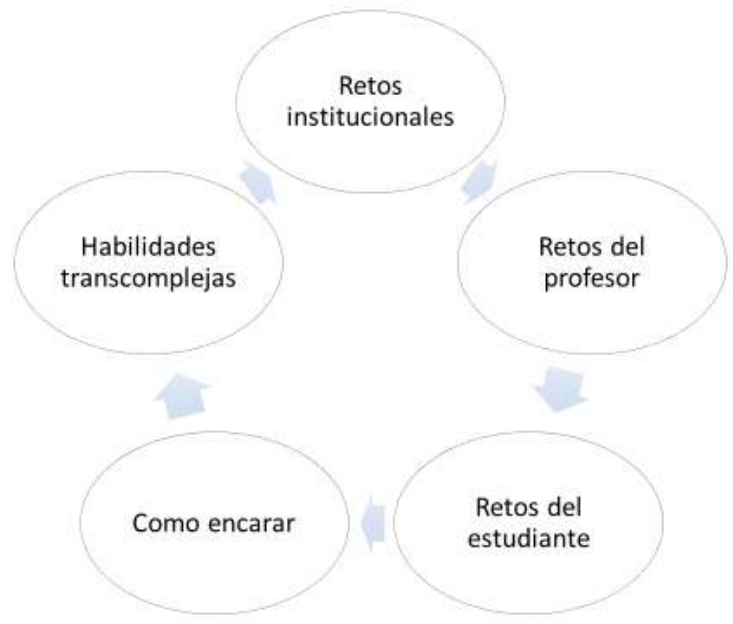

Fuente: Elaboración propia.

Retos institucionales: poco analizados y muy visibles de manera social ante medios de comunicación y los gobiernos y criticados por la comunidad. Por un lado, está el factor motivacional muy afectado por el hecho de no tener de manera física al estudiante y tampoco una actividad regular académica y administrativa. Por otro lado, está la respuesta social de la institución educativa ante la pandemia muy diferente en una situación pública o privada, provocando preocupaciones con la exclusión escolar, especialmente que se 
agrava con la profundización de la injusticia social. Finalmente, el factor administrativo y económico de obligaciones internas y externas.

Retos del profesor: el primero y muy importante, es el motivacional, que debe y está obligado a tenerlo muy en alto en comparación con sus estudiantes. Los profesores se ven afectados en no tener al estudiante de manera física y los escenarios o contextos educativos son diversos e inclusive adversos e incluso injustos socialmente. La planificación y la didáctica implican mayores tiempos de estructuración por implicar diferentes estrategias para llegar al estudiante, esto es más que estar frente a un ordenador. La teoría y práctica están inmersos en contextos virtualizados y el profesor debe intuir muchas veces dónde está su estudiante. El tiempo y el espacio son diversos, adversos y creativos.

Retos del estudiante: los retos más importantes de los actores educativos,sin lugar a duda, son estos. Primeramente y más importante están las condiciones para la motivación intrínseca y extrínseca, que al estar lejos de su escuela o institución y, depende del estudiante tener incluso estructura física para transformar su hogar en su escuela, lo que hace que muchos enfrenten una verdadera crisis. Este reto está casado al aislamiento que debe ser manejado de manera biológica y psicológica.

El estar confinado también lo lleva a tener diversos niveles de estrés y ansiedad; esta última muy complicada dependiendo el escenario donde se encuentre el estudiante y el tiempo de confinamiento. Además, estar en casa durante varios días e incluso semanas lleva al estudiante al sedentarismo y a la no práctica de algún deporte, además de no recibir los rayos solares.

El gran reto para el sistema educativo de cada país es pensar que todos los estudiantes tienen el mismo nivel de alfabetización digital, que todos tienen acceso a internet y que todos pueden tener acceso a un ordenador o celular, lo que es totalmente falso, convirtiéndose en una barrera o factor de desigualdad social e incluso discriminatorio. Por lo tanto, la falta de ambientes adecuados de aprendizaje es un tema muy importante, pues el escenario puede en muchos casos ser adverso, los padres en roles de profesores multidisciplinares, o a la inversa, padres ausentes más preocupados por la coyuntura de emergencia sanitaria. Finalmente, el cuerpo humano llega a mostrar en estos escenarios adversos cansancio físico y mental.

Como encarar: aquí el hogar, la familia y los contextos que el confinamiento otorga son claves, los procesos que las herramientas y los 
medios del hogar ofrecen, la música, la práctica de algún deporte, el arte en todas sus expresiones, la práctica de la lectura y escritura, la asignación de roles en el hogar como parte del surgimiento de tareas propias del confinamiento y que aterrizan muchas veces en la solución de problemas, este último punto será permanente y una práctica muy común en la post-pandemia. A esas condiciones se agrupan las que dependen de que los países estén dispuestos a invertir recursos para facilitar el acceso a la tecnología, haciendo del virtual una posibilidad global para que la inclusión escolar sea una forma de contribuir a la justicia social. Es una cuestión de responsabilidades compartidas entre los sistemas, las escuelas y sus profesionales y los estudiantes y sus familias.

Habilidades educativas emergentes: las habilidades planteadas forman parte de una pedagogía o andragogía emergente que valoramos como 'R3 Resiliente, Religante y Reinventante', y que están valoradas desde el pensamiento complejo y la transdisciplinariedad como pilares aplicativos. Resiliente porque los actores educativos, a partir del proceso de pandemia y más aún en post-pandemia, deben sin lugar a duda salir de su adversidad, luchar por ser mejores, autocuidarse y valorar cada momento, es decir, hacia una educación de la vida y por la vida. Religante, pues el acto de conectividad en estos procesos ha sido muy grande, de unir y desunir procesos, acciones, miradas, pensamientos y todo lo que el ser humano está construyendo. Finalmente, reinventante, pues esta pandemia nos ha llevado y nos llevará a reinventar al ser humano todos los días y en todo momento.

Llamamos habilidades transcomplejas, pues nacen principalmente en la aplicación de los fundamentos epistemológicos y filosóficos del paradigma transcomplejo y, por lo tanto, de la Teoría Educativa Transcompleja: resiliencia, creatividad, religar, pensamiento complejo, visión transdisciplinar, empatía, comunicación activa, adaptabilidad, autopoyesis, aula mente social, digitales reinventarse, lectura y escritura, observador y la habilidad para resolver problemas. Todas ellas harán del estudiante en pandemia y postpandemia un sujeto diferente y capaz de afrontar su autocuidado, su autoaprendizaje bajo entornos de aprendizaje nuevos y con la capacidad del estar y no estar con el otro en unidad y diversidad (véase Cuadro 2). 
Cuadro 2 - Educación en Pandemia y Postpandemia COVID-19

\begin{tabular}{|c|c|}
\hline \multicolumn{2}{|c|}{$\begin{array}{l}\text { Retos Institucionales } \\
\text { Motivacional } \\
\text { No tener de manera fisica al estudiante } \\
\text { Respuesta social de la Escuela } \\
\text { Administrativos y económicos }\end{array}$} \\
\hline $\begin{array}{l}\text { Retos del Profesor } \\
\text { Motivación } \\
\text { No tener de manera física al estudiante } \\
\text { Nuevas maneras de planificar el aula y sus didácticas } \\
\text { El valor de los contenidos mínimos de aprendizaje } \\
\text { Teoria y práctica basada en modelos virtualizados } \\
\text { Manejo de tiempo y espacio }\end{array}$ & $\begin{array}{l}\text { Retos del estudiante } \\
\text { Motivación } \\
\text { Aislamiento } \\
\text { Estrés y ansiedad del estudiante } \\
\text { Analfabetismo digital } \\
\text { Sedentarismo } \\
\text { Falta de ambientes adecuados para el aprendizaje } \\
\text { Padres en rol de profesor } \\
\text { Padres ausentes } \\
\text { Cansancio físico y mental por confinamiento }\end{array}$ \\
\hline
\end{tabular}

Fuente: Elaboración propia.

Una breve mirada sobre los retos posibilita que se observe que la educación en sí misma es una estrategia metacognitiva muy importante en esto momento para tomar conciencia del cuidado de la salud y para aprender a moverse por escenarios de autoaprendizaje de manera multidimensional. El mundo ya no será el mismo durante varios años, incluso décadas; la pandemia está siendo un examen muy duro para la humanidad donde nos refleja la gran vulnerabilidad del ser humano y la incapacidad para prevenir y afrontar situaciones mundiales de emergencia sanitaria.

En este momento, además de las condiciones ya presentadas, los sistemas educativos deben ser capaces de aportar estratégicamente a aplanar la curva de contagios (véase Figura 3) de manera invisible y visible en hechos y para esto los procesos pedagógicos y andragógicos deben generar procesos de metamorfosis. 
Figura 3 - Aplanamiento de la curva pandémica vs sistemas educativos

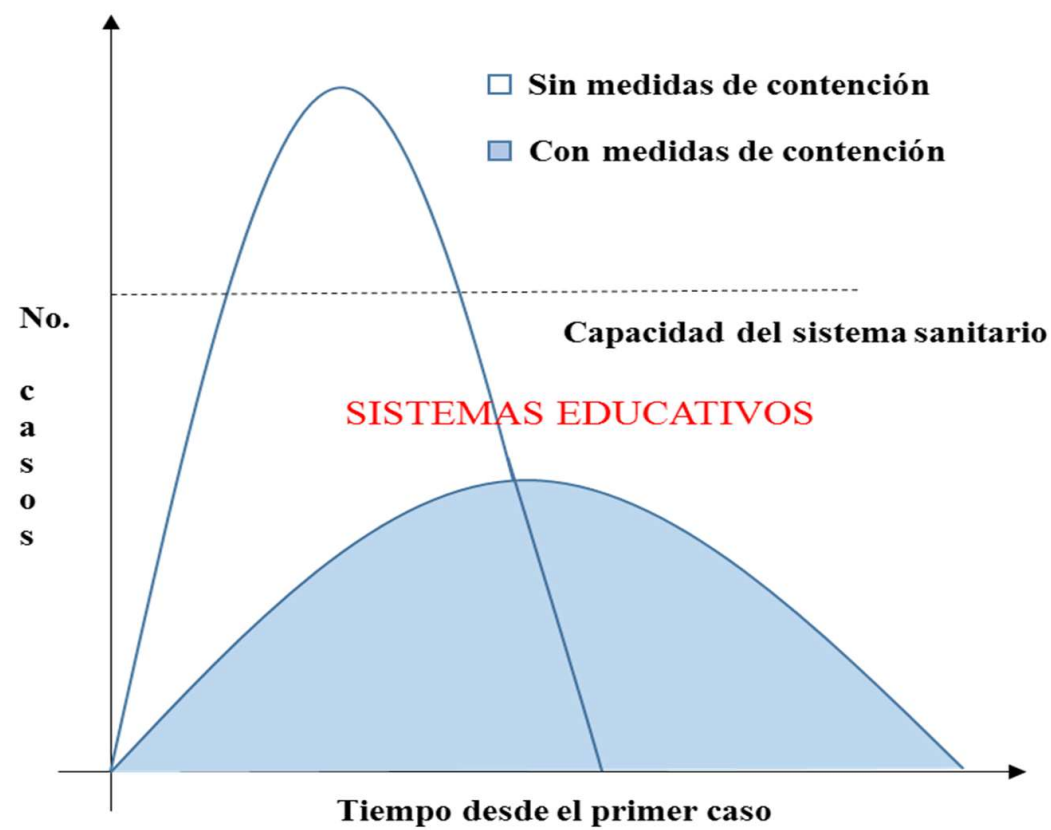

Fuente: Elaboración propia.

Finalmente, hay que reconocer que la población en este proceso pandémico ha entrado en un autoaprendizaje y autocuidado de la salud y los procesos educativos presenciales entran en un cambio de paradigma donde el estudiante ya no es visible, se ha virtualizado. Son cambios muy grandes en poco tiempo y, mismo que las aulas presenciales vuelvan poco a poco, las clases ya no podrán ser las mismas.

\section{Discusiones}

En poco tiempo, los países del mundo tomaron la decisión de entrar en cuarentena, y las escuelas y universidades fueron las primeras en hacerlo. El reporte de la UNESCO (2020) señala que se ha afectado alrededor del 70\% 
de la población estudiantil del mundo. Varios otros países han implementado cierres localizados que impactan a millones de estudiantes adicionales.

Actualmente en el planeta, muchos sistemas educativos nacionales continúan con la formación virtualizada, otros retornaron con extremas medidas de bioseguridad y otros más no cambiaron su sistema presencial de enseñanza-aprendizaje. Lo cierto es que más de la mitad de los estudiantes del planeta tuvieron que adaptar estrategias para seguir conectados a las escuelas, involucrándose en nuevas condiciones, muchas tampoco accesibles para todos, comprobando que surgen nuevos retos, nuevas estrategias educativas emergentes (véase Cuadro 2).

Por esto, la preocupación de analizar en este artículo la realidad educativa en este proceso de Pandemia, especialmente en lo que sucede con los autores educativos, especialmente con los estudiantes, los profesores y las instituciones educativas. En este breve diagnóstico se observan retos y algunas posibilidades de cómo encarar estos nuevos escenarios, incluso con el surgimiento de habilidades que no están en contextos presenciales y de equilibrio, sino en adversidad, y que son las habilidades transcomplejas.

En la actualidad, quizás, nunca se ha observado tan bien como ahora, la necesidad de ser resiliente, religante y reiventante al trabajar en las instituciones educativas. En este sentido, además de la infraestructura de responsabilidad de los países y sus sistemas educativos, las habilidades transcomplejas son una manera de traer respuesta frente a una nueva realidad, por eso hay que se tener en cuenta estrategias que conecten las clases a lo que es real y moverse delante lo que es incierto.

La identificación de bloques categoriales con la codificación abierta indica que las contribuciones de González (2009) y de la OMS (2020) convergen con otros estudios que se han dedicado a reflexionar sobre la relevancia de cambios paradigmáticos en el ámbito educacional. En este sentido, Behrens y Prigol (2020, p. 724) alertan que "El planeta pasa por una crisis existencial en la cual los individuos privilegian el tener, en detrimento del ser [...]". Para las autoras "[...] Esa constatación merece un cambio epistemológico urgente para que la humanidad pueda acoger un posicionamiento más ético y solidario en todas las dimensiones", valorando el compromiso con la justicia social.

Una educación conectada con la complexidad y trabajada a partir de una perspectiva transdisciplinar destacada en los bloques concilia con estudios 
de Zwierewicz et al. (2020, p. 694) cuando afirman que la articulación entre la complexidad y la transdisciplinariedad, apoyadas por la ecoformación, colaboran para que los estudiantes puedan "[...] acceder, profundizar, construir y difundir conocimientos y soluciones en conexión con la realidad".

En este sentido, el carácter religante del currículo se transforma en una de las condiciones fundamentales para la educación ya que "[...] posibilita entrelazar conocimientos, ideas, principios y aplicar la complejidad en cualquier actividad y situación" (GONZÁLEZ, 2017, p. 1). Esa perspectiva converge con bloques identificados en el artículo de la OMS (2020), especialmente cuando destacan la relevancia de adaptar estrategias en función de los riesgos del momento vivido.

En ese sentido hay que dar atención a lo que está más allá del espacio de las clases. Moraes y Torre (2018) hablan del aprendizaje integrado, que puede ocurrir dentro o fuera del ámbito escolar. Según los autores, el aprendizaje integrado "[...] es un proceso mediante el cual construimos nuevos significados de las cosas y del mundo que nos rodea [...], pero también "[...] mejoramos nuestras estructuras y habilidades cognitivas, desarrollamos nuevas habilidades, modificamos nuestras actitudes y valores proyectando tales cambios en la vida, en las relaciones sociales y laborales [...]” (p. 89-90).

A pesar del punto que hemos llegado en 2020, Morin, Ciurana y Motta (2005) han destacado que la historia humana empezó por una diáspora planetaria y esta llevó a una extraordinaria diversidad de lenguas, culturas, destinos, fuentes de innovación y de creación en todos los dominios. Así que, la riqueza de la humanidad reside en su diversidad creadora, pero la fuente de su creatividad está en su unidad generadora. Esto es uno de los puntos de convergencia entre los bloques, especialmente si hay interés en invertir en una teoría educativa innovadora, motivadora del pensamiento complejo y de la transdisciplinariedad, y que pueda utilizar de la investigación y de la innovación para mitigar la transmisión del SARS-CoV2 que seguirá ocurriendo hasta que por fin una vacuna llegue a los billones de habitantes de la Tierra.

Esa perspectiva indica el valor de las categorías centrales 'aula mente social, currículo transcomplejo y estrategia educativa' identificados en el artículo de González (2009) y 'la estrategia emergente en salud, el trabajo comunitario y los procesos adaptativos' en el artículo de la OMS (2020). Esto significa un cambio paradigmático que implica saltar de una visión sobre la 
educación a la otra y que expresa el compromiso con la inclusión y la justicia social y el valor la resiliencia frente la diversidad creadora. Es la resiliencia que ayuda a abrir caminos para ser religante y reinventante, pero es también cuando se religa y se reinventa que la resiliencia más se expresa.

El cambio paradigmático representa retos para los gobiernos y sus sistemas educativos, pero también específicamente para los docentes, para los estudiantes y para las escuelas. El reto del profesor se desarrolla en el planteamiento del trabajo, que pasa por una acción educativa intencional, buscando organizar acciones y prever resultados relevantes, teniendo en cuenta el acceso, profundización y construcción del y conocimiento articulada a posibilidades para solucionar problemas e intervenir en la realidad, atendiendo de esa forma, expectativas y demandas de los propios estudiantes. Es importante que el profesorado haga la transposición de todo el conocimiento teórico aprehendido en saberes pedagógicos y sociales, creando estrategias que tengan significado para los estudiantes.

El profesor como constructor de realidad, debe crear medios de aprendizaje donde el estudiante pueda aprender de forma global e integrada. La confluencia de estrategias creativas, transdisciplinarias, complejas y transcomplejas, sumada a intencionalidad del planteamiento del trabajo a la acción efectiva, potencializa y fortalece el desarrollo de la educación como R3 Resiliente, Religante y Reinventante. Esa es una condición crucial para superar lo que Morin (2009, p. 13) indica como "[...] inadecuación cada vez más amplia, profunda y grabe entre os saberes separados, fragmentados, compartimentados entre asignaturas y, por otro lado, realidades o problemas cada vez más $[\ldots .$.$] globales, planetarios”.$

El reto del estudiante, implica también invertir en energías cognitivas e imaginarias. Esto ayuda al estudiante a reflejar, colabora en la organización del pensamiento de manera que pueda sintetizar las ideas más significativas en un ejercicio de apropiación del conocimiento. Así, el reto cómo encarar por medio del aprendizaje integrado, puede construir en un entorno formal o no formal, que son elementos imprescindibles en el aprendizaje para la vida, además de necesarios para la adquisición de habilidades transcomplejas.

Para estimular al estudiante a ser generador de diferentes formas de manifestación expresiva, es necesario llévalos al mundo y no solamente el mundo a ellos. Ir al teatro, al cine, pasear por las plazas, visitar museos, asistir a presentaciones de música, utilizar las bibliotecas, pasear por los zoológicos, 
conocer la historia de la ciudad. Bien como costumbres, tradiciones, comidas regionales, entre otros, es una práctica que favorece el aprendizaje integral y es una manera de ampliar el campo de las curiosidades además de atribuir y potenciar experiencias significativas y funcionales. Cuando no son posibles presencialmente, hay que crear posibilidades remotas que involucren actividades simuladas.

Aún con los retos, al elegirnos habilidades transcomplejas como forma de educar, se puede utilizar de diferentes métodos como posibilidades efectivas de innovar, crear, superar y aprender a partir de la adversidad. Así, de la misma manera que la Teoría Educativa Transcompleja, la complejidad se opone al conocimiento ordenado, lineal y sistematizado, ya que la complejidad es "[...] un tipo de pensamiento que no separa, pero une y busca las relaciones existentes entre los diversos aspectos de la vida. Se trata de un pensamiento que integra los diferentes modos de pensar, y se opone a cualquier mecanismo disyuntivo" (PETRAGLIA, 2013, p. 16).

\section{Conclusiones como expresión de la Teoría Formal}

A partir del análisis dispuesto de manera multidimensional del artículo de González (2009) y de la OMS (2020), se ha logrado encarar que mientras enfrentamos adversidades, pueden surgir propuestas que nacen en el paradigma emergente donde se encuentra el pensamiento complejo, la transdisciplinariedad y la transcomplejidad. Son cambios paradigmáticos que se comprometen con la superación de la estructura rígida de los procesos de enseñanza y de aprendizaje y pueden colaborar con la inclusión escolar que una condiciones indispensables de la justicia social.

Así que, el currículo ya no es posible verlo como una estructura lineal, rígida, inmerso en sub y especialidades, con contenidos disciplinares y bajo propuestas a manera de recetas. El currículo ahora necesita ser transcomplejo, inmerso en procesos emergentes, religados y con infinidad de caminos transdisciplinares. Es este currículo que valora y potencia habilidades transcomplejas.

Las habilidades transcomplejas son imprescindibles para que los estudiantes, además de acceder a los conocimientos históricamente construidos, puedan no sólo profundizarlos, pero también resignificarlos a partir de sus propios contextos, además de crear nuevas posibilidades mientras 
generan e invierten soluciones en su propia realidad. Ellas constituyen una manera de traer respuesta frente a una nueva realidad y pueden ser impulsadas cuando se promueven estrategias que conecten las clases a lo que es real y colaboran para que los estudiantes se muevan delante lo que es incierto.

Esa perspectiva implica saltar de una visión sobre la educación atomizada a la otra que caracteriza una educación atenta a la complejidad y apoyada por la transdisciplinariedad. Una educación que expresa el valor, la resiliencia frente la diversidad creadora, ya que la resiliencia ayuda a abrir caminos para ser religante y reinventante y es al ser religante y reinventante que la resiliencia se fortalece.

\section{Referências}

BEHRENS, M. A.; PRIGOL, E. L. Avanços do pensamento complexo na visão ética. DOI: https://doi.org/10.28998/2175-6600.2020v12n28p724738. Revista Debates em Educação, Maceió, v. 12, n. 28, p. 725-738. 2020, Disponible en: https://www.seer.ufal.br/index.php/debateseducacao/article/view/9862. Acceso en: 29 set. 2020.

CHENG, V. et al. Severe Acute Respiratory Syndrome Coronavirus as an Agent of Emerging and Reemerging Infection. Clinical Microbiology Reviews, [s. l.], v, 20, n, 4, 2020. DOI: https://doi.org/10.1128/cmr.00023-07 Disponíble en: https://cmr.asm.org/content/20/4/660. Acceso en: 20 set. 2020.

GLASER, B.; STRAUSS, A. The Discovery of the Grounded Theory. Strategies for Qualitative analysis. Nueva Jersey: Aldine Transaccion, 1967.

GONZÁLEZ, J. M. Educación emergente: el paradigma del siglo XXI. La Paz: PRISA, 2017.

GONZÁLEZ, J. M. El aula mente social como potencial creativo en la educación: enfoque desde el pensamiento complejo. Revista Cientifica de Publicación del Centro Psicopedagógico y de Investigación en Educación Superior, La Paz, v., $\quad$ n. $1 . \quad$ Disponible en: http://ojs.cepies.umsa.bo/index.php/RCV/article/view/29. Acceso en: 16 ago. 2020 . 
GONZÁLEZ, J. M. Teoría Educativa Transcompleja. La Paz: IIICAB Bolivia, 2009.

HOLSHUE, M, et al. First Case of 2019 Novel Coronavirus in the United States. The New England Journal of Medicine, [s. l.], v. 382, n. 4, p. 929-936, 2020. DOI: https://doi.org/10.1056 / NEJMoa2001191. Disponible en: https://www.nejm.org/doi/full/10.1056/NEJMoa2001191. Acceso en: 16 ago. 2020.

LU, H., STRATTON; TANG, C. Outbreak of pneumonia of unknown etiology in wuhan China: the mystery and the miracle. J. Med. Virol, v. 4, p. 401-402, 2020. DOI: https://doi.org/10.1002/jmv.25678. Disponible en: https://onlinelibrary.wiley.com/doi/epdf/10.1002/jmv.25678. Acceso en: 22 set. 2020 .

MORAES, M. C. Além da aprendizagem: um paradigma para a vida. In: MORAES, M. C.; TORRE, S. (Org.). Sentipensar: fundamentos e estratégias para reencantar a educação.2. ed. Petrópolis: Vozes, 2018. p. 19-25.

MORAES, M. C.; TORRE, S. Sentipensar: fundamentos e estratégias para reencantar a educação. 2. ed. Rio de Janeiro: Wak, 2018.

MORIN, E. Ensinar a viver: manifesto para mudar a educaçâo. Traducción de Edgard de Assis Carvalho y Mariza Perassi Bosco. Porto Alegre: Sulina, 2015.

MORIN, E. A cabeça bem-feita: repensar a reforma, reformar o pensamento. 16. ed. Traducción de Eloá Jacobina. Rio de Enero: Bertrand Brasil, 2009.

MORIN, E.; CIURANA, R.; MOTTA, R. Educar na era planetária: o pensamento complexo como método de aprendizagem pelo erro e incerteza humana. 3. ed. São Paulo: Cortez. Brasilia: UNESCO, 2003.

MORIN, E.; DELGADO, C. J. Reinventar la educación: abrir caminos a la metamorfosis de la humanidad. La Havana: Editorial UH, 2017.

MORIN, E.; KERN, A. B. (2005). Terra-Pátria. 5. ed. Traducción de Paulo Azevedo Neves da Silva. Porto Alegre: Sulina.

MORIN, Edgar. Os sete saberes necessários à educação do futuro.12. ed. Traducción de Eleonora F. da Silva y Jeanne Sawaya. São Paulo: Cortez. Brasília: UNESCO, 2007. 
OMS. Actualización de la Estrategia Frente a la COVID-19. Ginebra Suiza: Organización Mundial De La Salud, 2020.

PETRAgliA, I. Pensamento complexo e educação. São Paulo: Livraria da Física, 2013.

UNESCO. COVID-19 Respuesta. Madrid. Paris: UNESCO, 2020. Disponible en: https://es.unesco.org/covid19. Acceso en: 17 set. 2020.

VELAVAN, T.; MEYER, C.The COVID-19 epidemic. Trop Med Int Health, [s. l.], v. 25, n. 3, p. 278-280. DOI: https://doi.org/10.1111/tmi.13383 Disponible en: https://www.ncbi.nlm.nih.gov/pmc/articles/PMC7169770/. Acceso en: 12 set. 2020.

WANG, W.; TANG, J.; WEI, F. Updated understanding of the outbreak of 2019 novel coronavirus (2019-nCoV) in Wuhan. China. Journal of Medical Virology, $[s . \quad$ l], $\quad$ v. 20 n. 3, p. 441-447, 2020. DOI: https://doi.org/10.1002/jmv.25689 Disponible en: https://www.ncbi.nlm.nih.gov/pmc/articles/PMC7167192/. Acceso en: 25 set. 2020 .

WERNECK, G. L.; CARVALHO, M. S. A pandemia de COVID-19 no Brasil: crônica de uma crise sanitária anunciada. Cadernos de Saúde Pública, Rio de Enero, v. 36, n. 5, p. 1-4, 2020. DOI: https://doi.org/10.1590/0102$311 \times 00068820$. Disponible en: https://www.arca.fiocruz.br/handle/icict/41242. Acceso en: 29 set. 2020.

ZWIEREWICZ, M. et al. Pensamento complexo, transdisciplinaridade e ecoformação na Educação Básica e suas implicaçóes em pesquisas com intervenção. Revista Debates em Educação, Maceió, v. 12, n. 28, p. 691-704. 2020, DOI: http://dx.doi.org/10.28998/2175-6600.2020v12n28p691-704. Disponible en: https://www.seer.ufal.br/index.php/debateseducacao/article/view/9775. Acceso en: 29 set. 2020.

Recebido em: 03 ago. 2020

Aceito em: 28 ago. 2020 